\title{
El ocaso de la televisión pública española ante su audiencia: un lustro decadente (2010-2015)
}

\section{Natalia Quintas-Froufe ${ }^{1}$}

Recibido: 2016-06-27

Enviado a pares: 2016-08-03
Aprobado por pares: 2016-11-15

Aceptado: 2017-01-13

DOI: 10.5294/pacla.2018.21.1.8

Para citar este artículo / to reference this article / para citar este artigo

Quintas-Froufe, N. (2018). El ocaso de la televisión pública española ante su audiencia: un Iustro decadente. Palabra Clave, 21(1), 165-190. DOI: 10.5294/pacla.2018.21.1.8

\section{Resumen}

La televisión pública española ha sufrido una grave pérdida de audiencia durante el lustro 2010-2015. Este periodo estuvo marcado por la implantación de la televisión digital terrestre en España, la eliminación de la publicidad comercial en los canales públicos y el nuevo marco jurídico que introdujo la Ley General del Comunicación Audiovisual (2010), aspectos que afectarían directamente a la audiencia televisiva. El presente artículo tiene por objetivo profundizar en el conocimiento y comportamiento de la audiencia española en relación con todos los canales de la corporación pública (La 1, La 2, Clan, tdp y 24 horas) desde el año de la transición digital (2010) a la actualidad (2015). Se presta una especial atención a La 1 por ser la principal cadena generalista del grupo. Los objetivos de investigación son los siguientes: conocer el perfil del espectador español en relación con el medio televisivo y analizar el comportamiento longitudinal de la audiencia respecto de todos los canales de la corporación pública. Para ello, en esta investigación, se describirá la identidad de cada canal a través de su oferta programática para finalmente exponer el análisis longitudinal de los

1 orcid.org/0000-0001-7597-6516. Universidade da Coruña, España. n.quintas.froufe@udc.es 
índices de audiencia de cada una de las cadenas. La metodología empleada ha sido la del estudio de caso. Se concluye que, si esta tendencia continúa, la oferta televisiva de la televisión pública, respecto de las audiencias, lleva camino de convertirse en puramente testimonial.

\section{Palabras clave}

Televisión, audiencia, España, televisión pública, espectadores (Fuente: Tesauro de la Unesco). 


\section{The Downfall of Public Television in Spain before its Audience: Five Years in Decline (2010-2015)}

\section{Abstract}

Spanish public television has suffered a serious loss of audience during the five-year period between 2010 and 2015. This period was marked by the introduction of digital terrestrial television in Spain, the elimination of commercial advertising in public channels and the new legal framework introduced by the General Law of Audiovisual Communication (2010), all of which are aspects that directly affected the television audience. The purpose of this paper is to gain a greater knowledge of Spanish audience and its behavior with regards to all public channels (La 1, La 2, Clan, tdp and 24 horas) from the year of digital transition (2010) to this day (2015). We will focus particularly on La 1 , as the main generalist network of the group. The objectives of the research are the following: to become familiar with the Spanish viewer's profile with regards to the television medium and to analyze the longitudinal behavior of the audience regarding all public channels. The methodology used was the case study. It is concluded that, if this trend continues, the public television offer regarding audience is on the way to becoming purely testimonial.

\section{Keywords}

Television; audience; Spain; public television; viewers (Source: Unesco Thesaurus). 


\section{0 ocaso da televisão pública espanhola diante da sua audiência: um lustro decadente (2010-2015)}

\section{Resumo}

A televisão pública espanhola tem sofrido uma grave perda de audiência durante o lustro 2010-2015. Este período foi marcado pela implantação da televisão digital terrestre na Espanha, a eliminação da publicidade comercial nos canais públicos e o novo marco jurídico introduzido pela Lei Geral de Comunicação Audiovisual (2010), aspectos que afetariam diretamente a audiência da televisão. $O$ presente artigo tem por objetivo aprofundar no conhecimento e comportamento da audiência espanhola com relação a todos os canais da corporação pública (La 1, La 2, Clan, tdp e 24 horas) desde o ano da transição digital (2010) até hoje (2015). Prestaremos uma especial atenção a La 1 por ser a principal cadeia generalista do grupo. Os objetivos de pesquisa são os seguintes: conhecer o perfil do espectador espanhol em relação com a mídia televisiva e analisar o comportamento longitudinal da audiência com relação a todos os canais da corporação pública. A metodologia empregada foi a do estudo de caso. Conclui-se que, se esta tendência continuar, a oferta de televisão da televisão pública, com relação à audiência, estará a caminho de transformar-se apenas em testemunhos.

\section{Palavras-chave}

Televisão; audiência; Espanha; televisão pública; espectadores (Fonte: Tesauro da Unesco). 


\section{Introducción y contextualización}

El escenario audiovisual en España ha cambiado radicalmente en el último lustro. El 2010 marcó un punto de inflexión en el contexto televisivo por varios motivos. Por una parte, la implantación de la televisión digital terrestre, cuya última fase tuvo lugar en abril de 2010, multiplicó el número de canales y la consiguiente oferta televisiva, a la vez que trajo consigo una mayor fragmentación de la audiencia iniciada con la llegada de los tres primeros canales privados en la década de 1990. Este hecho, como apunta Roel (2014), puso fin a la etapa dorada de Televisión Española y marcó el paso de las audiencias cautivas a las compartidas.

Por otra parte, los cinco grupos empresariales dominantes hasta el momento (Radio Televisión Española, Atresmedia, Mediaset España, Veo TV y Net TV) optaron por fortalecerse siguiendo estrategias de fusión y absorción fruto del nuevo marco jurídico que impulsó la entrada en vigor de la Ley General del Comunicación Audiovisual el 1 de mayo de 2010, más permisivo en esta materia. De este modo, se asistió a la re-configuración del sector tras la fusión de Gestevisión (Telecinco) y Sogecuatro (Cuatro) en 2011 y, un año después, a la absorción de la Sexta por Atresmedia. Dichas estrategias dieron lugar a la consolidación de un duopolio (Mediaset España y Atresmedia) que modificó la cadena de valor de la televisión (García-Santamaría, 2013), y que concentra en la actualidad a $58.4 \%$ de la audiencia española y a $88.5 \%$ de los ingresos publicitarios de la televisión en abierto (Cnmc.es, 2015).

Este nuevo marco jurídico también afectaría especialmente a la Corporación RTVE por ser el marco general de la prestación del servicio público (Díaz, 2012). El modelo televisivo público español ya es complejo de por sí y desde sus orígenes se concibió como un modelo singular en el contexto europeo de las emisoras públicas (Palacio, 2007), entre otras causas, por su gestión financiera. La financiación mixta (los ingresos procedentes de los presupuestos generales del Estado y los ingresos procedentes de la facturación publicitaria) difiere de la de cualquier otro servicio público en Europa basado en el modelo de canon o impuesto televisivo y condiciona además aspectos vitales para la misión de servicio público de 
comunicación, como la independencia, la gratuidad y la calidad de los contenidos (Soler, 2012).

En 2010, también tuvo lugar uno de los cambios más relevantes en el modelo de gestión de la Corporación: la eliminación de la publicidad comercial tras la entrada en vigor de la Ley de Financiación de la Corporación de Radio y Televisión Española (Ley 8/2009, de 28 de agosto). Las primeras consecuencias inmediatas que se preveían para la cadena pública serían disponer de más horas de programación y gozar de una posición ventajosa ante la audiencia por presentar una parrilla de programación ausente de publicidad (Quintas-Froufe, 2013). La supresión de esos ingresos comerciales por parte de la Corporación supuso que los operadores privados asumieran dicha cuota de mercado que se distribuyeron de nuevo la tarta publicitaria y se beneficiaron fuertemente de dicha situación. Dicha eliminación supuso absorber el $25 \%$ de la oferta de espacios publicitarios nacionales en el medio (Bustamante y Corredor, 2012).

En este contexto, marcado fuertemente por la crisis económica y por la transformación tecnológica en la que está inmersa el mercado audiovisual, la televisión pública sufrió el desapego de la sociedad española, como se mostró en la continua pérdida de su audiencia. Si bien el objetivo de una televisión de servicio público no es aglutinar audiencias masivas, ya que se rige por otros principios de programación ajenos a los comerciales, como se planteará posteriormente en este estudio, sí resulta llamativo ese distanciamiento con la ciudadanía plasmado en el descenso de las cuotas de audiencia de todas las cadenas de RTVE que le llevó a alcanzar mínimos históricos.

Bien es cierto que una televisión pública es aquella que "no vende nada a nadie" (Bustamante, 1999), pero en este caso se produce una contradicción entre el deber como servicio público y lo que "funciona" en la televisión, como explican López y Valderrama (2011). Tal como consideran estas autoras, los contenidos en sintonía con la misión de servicio público no canalizan a seguidores suficientes, lo cual conlleva no contar con respaldo económico para continuar con la emisión de los programas y al poco tiempo desaparecen de las parrillas. 


\section{Material y metodología}

El presente artículo tiene como finalidad profundizar en el conocimiento y comportamiento de la audiencia española en relación con todos los canales de la corporación pública (La 1, La 2, Clan, tdp y 24 horas) desde el año de la transición digital (2010) a la actualidad (2015). Se prestará una especial atención a La 1 por ser la principal cadena generalista del grupo.

Los objetivos de investigación son los siguientes: en primer lugar, conocer el perfil del espectador español en relación con el medio televisivo; y en segundo lugar, analizar el comportamiento longitudinal de la audiencia respecto de todos los canales de la corporación pública. Para cumplir dichos objetivos, se ofrece el perfil medio del espectador español en relación con las características sociodemográficas y su consumo televisivo; y posteriormente se lleva a cabo una breve descripción de la identidad del canal a través de su oferta programática y de los principales géneros emitidos para finalmente exponer el análisis longitudinal de los índices de audiencia de cada una de las cadenas.

Los indicadores seleccionados para realizar el análisis fueron los índices de audiencia, debido a que son uno de los modos de conocer a la audiencia, ya que al abarcar amplias muestras son la única maquinaria capaz de dar una imagen completa de la audiencia de televisión de un país (Huertas, 2002). En esta investigación, se ha seleccionado la cuota de pantalla o share por ser el índice unánimemente aceptado en el estudio de las audiencias televisivas y por ser el dato que privilegia el concepto de competencia, frente al rating, que al indicar el porcentaje de espectadores sobre la población en total se centra en el impacto (Cascajosa, 2016).

La metodología seleccionada es la del estudio de caso, ya que permite aproximarse a los actores de manera que se pueda realizar la comprensión e interpretación de sus acciones con cierto éxito (Coller, 2000) y por considerarse la más adecuada a esta investigación ceñida a un único objeto de estudio durante un tiempo limitado. 
Las principales fuentes de información a las que se acudió fueron las fundamentales en el ámbito de las audiencias televisivas en España: Kantar Media (empresa responsable de la medición de las audiencias en España), Barlovento Comunicación (consultora de comunicación) y la Asociación para la Investigación de Medios de Comunicación, junto con la literatura científica, principalmente ligada al contexto español, sobre dicha temática.

\section{El espectador español: perfil y consumo}

En la actualidad, la televisión, como el medio social por excelencia, no se usa de manera educativa, sino más bien como forma de entretenimiento y como herramienta para captar la máxima audiencia posible (De Casas Moreno, Maraver y Aguaded, 2016). Por ello, el ciudadano español se entretiene pero también se informa a través de la televisión, por lo que la figura del ciudadano ante la televisión supera los conceptos de espectador y de consumidor (García, 2011).

En España, la televisión es el medio más consumido y el que tiene la mayor penetración en el conjunto de los medios en el ámbito de la sociedad española (Aimc.es, 2016) y, en consecuencia, el que recibe una mayor inversión publicitaria (Infoadex.es, 2015). Conocer el perfil de la audiencia y el comportamiento de esta es fundamental, ya que la televisión es el medio de comunicación clave del consumo mediático habitual de la ciudadanía española.

El perfil del espectador español, en relación con las características sociodemográficas, apenas ha variado en el periodo estudiado: principalmente femenino (aunque con diferencias poco significativas entre hombres y mujeres), adulto (el segmento más representado es el de 65 años en adelante) y perteneciente a la clase social media (tabla 1 ). Se aprecia una falta de interés por este medio por parte de los segmentos de edad más jóvenes (de 14 a 19 y de 20 a 24). Cabe destacar que el universo del estudio general de medios son individuos mayores de 14 años y que desde febrero de 2015 la Asociación para la Investigación de Medios de Comunicación utiliza una nueva clasificación de la población que intenta representar la estructura actual de ingresos de los hogares españoles, fruto de la cual se han establecido siete 
grupos para distribuir a la población, desde el de mayor volumen de ingresos (IA1) hasta el de menor nivel de ingresos (IE2).

Tabla 1. Perfil del espectador televisivo español en función del sexo, la edad, la clase social (alta, media alta, media media, media baja y baja) expresado en porcentajes, penetración y tiempo de consumo (2010-2015)

\begin{tabular}{|c|c|c|c|c|c|c|c|c|c|c|c|c|c|c|c|c|}
\hline \multirow{2}{*}{ Año } & \multicolumn{2}{|c|}{ Sexo } & \multicolumn{7}{|c|}{ Edad } & \multicolumn{5}{|c|}{ Clase social } & \multirow{2}{*}{ 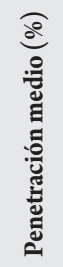 } & \multirow{2}{*}{ 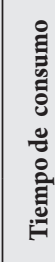 } \\
\hline & M & H & $\begin{array}{l}14- \\
19\end{array}$ & $\begin{array}{l}20- \\
24\end{array}$ & $\begin{array}{l}25- \\
34\end{array}$ & $\begin{array}{l}35- \\
44\end{array}$ & $\begin{array}{c}45- \\
54\end{array}$ & $\begin{array}{l}55- \\
64\end{array}$ & $\begin{array}{l}65 y \\
\text { más }\end{array}$ & A & MA & MM & MB & B & & \\
\hline 2010 & 51.1 & 48.9 & 6.5 & 6,2 & 17.4 & 19.3 & 16.8 & 13.2 & 20.5 & 9.6 & 16.3 & 43.3 & 25 & 5.8 & 87.9 & 234 \\
\hline 2011 & 51.2 & 48.8 & 6.5 & 6 & 16.9 & 19.3 & 17 & 13.4 & 20.9 & 10.2 & 16.6 & 43.3 & 24.4 & 5.4 & 88.5 & 239 \\
\hline 2012 & 51.6 & 48.4 & 6.4 & 5.9 & 16.1 & 19.3 & 17.4 & 13.6 & 21.4 & 10.4 & 17.1 & 44.3 & 23.2 & 5.1 & 89.1 & 246 \\
\hline 2013 & 51.5 & 48.5 & 6.3 & 5,7 & 14.9 & 19.4 & 17.9 & 13.9 & 22 & 10.1 & 17.5 & 43.9 & 23.3 & 5.1 & 88.7 & 244 \\
\hline 2014 & 51.2 & 48.8 & 6.3 & 5.5 & 14.1 & 19.2 & 18 & 14.2 & 22.6 & 10.9 & 17.6 & 43.4 & 23.1 & 4.9 & 88.3 & 239 \\
\hline 2015 & 51.2 & 48.8 & 6.4 & 5.5 & 13.5 & 18.9 & 18.1 & 14.6 & 23 & $\begin{array}{l}\text { IA1 } \\
6.45\end{array}$ & $\begin{array}{ll}\mathrm{IA2} & \mathrm{IH} \\
5 & 13.5\end{array}$ & $\begin{array}{c}\text { IC } \\
18.9\end{array}$ & $\begin{array}{ll}\mathrm{D} & \mathrm{IE} \\
18.1 & 1\end{array}$ & $\begin{array}{r}\text { IE2 } \\
6 \quad 23\end{array}$ & 88.2 & 234 \\
\hline
\end{tabular}

Fuente: Elaboración propia.

En un análisis longitudinal, se puede observar cómo apenas existen modificaciones relevantes en el perfil de la audiencia televisiva durante los cinco años analizados. Únicamente cabe señalar un cambio de comportamiento en la franja de edad de 25 a 34 (de $17.4 \%$ en 2010 a $13.5 \%$ en 2015).

En relación con el tiempo del consumo del medio, este alcanzó máximos históricos con los 246 minutos diarios en 2012 y los 244 minutos en 2013. El espectador español pasó más de cuatro horas al día de media viendo la televisión. En los años más duros de la crisis económica, el consumo se acentuó y alcanzó cuotas extraordinarias, lo cual llevó consigo que también se intensificara el consumo de mensajes, significantes y tecnologías (Callejo, 2007). Dicha intensificación puede constituir, como señala Sánchez-Tabernero (2015), un buen indicador de la aceptación de los contenidos televisivos. A partir de dicho año, el consumo televisivo desciende 
paulatinamente, aunque sería precipitado contemplar este descenso como una tendencia futura.

\section{La programación y el comportamiento longitudinal de la audiencia: La 1 y La 2}

La programación es una forma de hacer televisión pero también de consumirla (Gómez- Escalonilla, 1998). La forma de programar es un modo de construir la identidad de la cadena y es el medio de ofrecer el producto televisivo al espectador. El programador intenta ofertar un producto televisivo que llegue a la audiencia y que finalmente la fidelice, por lo que una cadena es los contenidos que ofrece (Herrero y Urgellés, 2015).

La programación de contenidos audiovisuales de RTVE está delimitada y regida por las obligaciones que posee como servicio público, estas se encuentran recogidas en la Ley 17/2006, de 5 de junio, de la radio y la televisión de titularidad estatal y también fueron publicados por el Instituto Oficial de Radio Televisión Española. El objeto de RTVE, tal como explica Díaz, es

una programación de servicio público que se caracteriza como programación de calidad (Preámbulos de la Ley y del Mandato-Marco) que haga compatible la rentabilidad social y la máxima cobertura (Preámbulo Mandato-Marco), una oferta general de contenidos audiovisuales que garantice la suficiente presencia en la sociedad (art.

7.1, último p. Mandato-Marco). (2012, p. 63)

La oferta programática de televisión española no se rige por criterios comerciales ni por la rentabilidad económica de los contenidos, ya que "el liderazgo de audiencia no es un fin para RTVE. El fin debe ser el cumplimiento de sus propios objetivos" (Instituto Oficial Radio y Televisión, s/f). En consecuencia, la Corporación RTVE debe adaptar la programación a contenidos relacionados con su función como servicio público. Los contenidos que tienen una mayor prioridad para el cumplimiento de este fin giran en torno, por ejemplo, a la protección de colectivos (tercera edad, menores, etc.). Cabe destacar que el 21 julio de 2010 el Consejo de Administración de RTVE aprobó el Código de autorregulación para la defensa de los derechos del menor en los contenidos audiovisuales, conexos, interactivos y de 
información en línea de la Corporación RTVE, en la línea del Código de autorregulación de contenidos televisivos e infancia, aprobado por TVE y otras cadenas comerciales (Antena 3, Tele 5 y Canal Plus) el 9 de diciembre de 2004 y firmado en colaboración con el Gobierno. También se reservan espacios significativos a contenidos culturales, infantiles, deportivos (Juegos Olímpicos, motociclismo, fútbol, etc.), informativos, divulgativos o entretenimiento para todos los públicos (López-Vidales, Azurmendi-Adarraga y Ortiz-Sobrino, 2012).

La Corporación RTVE distribuye su oferta televisiva en cinco canales distintos: dos cadenas generalistas: La 1 y La 2; y tres canales temáticos: Clan, Teledeporte y 24 Horas (tabla 2).

Tabla 2. Cuota de pantalla de los canales de la Corporación TVE (2010-2105)

\begin{tabular}{|c|c|c|c|c|c|c|}
\hline & $\mathbf{2 0 1 0}$ & $\mathbf{2 0 1 1}$ & $\mathbf{2 0 1 2}$ & $\mathbf{2 0 1 3}$ & $\mathbf{2 0 1 4}$ & $\mathbf{2 0 1 5}$ \\
\hline La 1 & 16 & 14.5 & 12.2 & 10.2 & 10 & 9.8 \\
\hline La 2 & 3.1 & 2.6 & 2.5 & 2.4 & 2.8 & 2.7 \\
\hline 24horas & 0.7 & 0.9 & 0.9 & 0.8 & 0.8 & 0.9 \\
\hline Clan & 3.2 & 3.2 & 2.5 & 2.4 & 2.3 & 2.4 \\
\hline tdp & 1.1 & 1 & 0.8 & 0.9 & 0.9 & 0.9 \\
\hline Total CRTVE & 24.1 & 22.2 & 18.9 & 16.7 & 16.8 & 16.7 \\
\hline
\end{tabular}

Fuente: Elaboración propia según Barlovento Comunicación.

A partir del análisis de las parrillas televisivas de los diferentes canales, se realiza, en primer lugar, una breve descripción de la identidad de cada una de las cadenas a través de su oferta de contenidos para posteriormente analizar los índices de audiencia obtenidos por el canal en el periodo estudiado.

\section{La 1: programación y comportamiento longitudinal de la audiencia}

El modelo de programación que sigue La 1 responde a una estructura horizontal (todos los días a la misma hora el mismo programa) durante la semana (a excepción de la franja de noche) y vertical el fin de semana para adaptarse a los hábitos de la audiencia (Fernández y Roel, 2014). 
Durante el periodo de análisis seleccionado la franja de mañana se ha mantenido sin apenas variaciones en la programación al estar principalmente destinada a los informativos y desayunos de RTVE seguidos del magacín La mañana de la 1, el programa de sociedad Corazón y el informativo. Por el contrario, la franja programática de la tarde ha sufrido continuas alteraciones al ser una de las más difíciles de consolidar ante la audiencia, de ahí que se haya reestructurado de forma constante mediante la inclusión de diversos formatos sin conseguir la ansiada fidelización del público.

En el periodo de estudio, se optó por introducir concursos con la estrategia stripping (programar de lunes a viernes a la misma hora el mismo contenido audiovisual) como Letris con Carlos Latre (2013), Jugamos en casa con los Morancos (2015) o El Legado de Ramón García (2015). Todos estos concursos fueron retirados por no cumplir las expectativas de audiencia de la cadena al alcanzar cuotas mínimas. Con esta franja, se produjo lo que algunos autores denominan un death slot, una ubicación en la parrilla de programación en la que los programas son eliminados por los bajos índices de audiencia (Villagrasa, 2011).

Otros formatos por los que se decidió apostar fueron los programas de entrevistas y testimonios, como Tenemos que hablar con Ana García Siñeriz (2013) o Entre todos, presentado por Toñi Moreno, que venía de alcanzar grandes cuotas en el canal autonómico andaluz, pero que tampoco lograron afianzarse en la parrilla. La excepción fue la serie de ficción Amar en tiempos revueltos emitida desde 2005 a 2012 y líder en esta franja horaria. Esta serie de ficción nacional sí consiguió durante los seis años de emisión fidelizar a la audiencia, pero finalmente la adquisición de los derechos por parte de Atresmedia provocó su eliminación de la parrilla televisiva de la cadena pública. Gran Reserva: el origen (2014), secuela de la exitosa serie de ficción Gran Reserva, fue introducida para cubrir el hueco dejado por Amar en tiempos revueltos, pero no logró atraer a los espectadores.

El prime time fue otra de las franjas en las que tampoco consiguió liderar con continuidad. Las series como La Señora (estrenada en 2011), Gran Reserva (estrenada en 2010), otras con carácter histórico como Isabel (es- 
trenada en 2012) o de aventuras como Águila Roja (estrenada en 2009), o la longeva Cuéntame cómo pasó (2001 - actualidad) fueron éxitos de audiencia para la cadena. Sin embargo, otros formatos de estreno como los programas de entretenimiento musical Generación Rock (2013) o Hit. La canción (2015), quisieron emular el éxito alcanzado por Operación Triunfo sin conseguirlo; o programas de entrevistas y actualidad como Así de claro, presentado por Ernesto Sáenz de Buruaga y emitido las noches de los lunes, fueron retirados por no haber alcanzado los objetivos esperados de audiencia.

En relación con los fines de semana, sí consiguió buenos resultados con la emisión de cine (la película de la semana) y lideró muchas de las noches de los domingos. Por el contrario, el prime time de los sábados destinado durante más de cuarenta años al programa Informe semanal sufrió un cambio de programación al ser relegado por el espacio musical Uno de los nuestros (2013) que no obtuvo los resultados previstos.

Cabe destacar que la Corporación TVE trató de adelantar el prime time en 2015 siguiendo las indicaciones del Ministerio de Sanidad, con el fin de contribuir a la racionalización de los horarios de los españoles. Sin embargo, dicho adelanto perjudicó directamente a la audiencia de muchas de sus emisiones nocturnas, por lo que se decidió suspender dicha medida.

En cuanto al comportamiento longitudinal de la audiencia, se observa que en 2010, primer año sin emisión de publicidad comercial, La 1 fue la cadena más vista en España durante todos los meses menos junio y julio por la retransmisión de la Copa Mundial de Fútbol por parte de Telecinco. Sin embargo, la eliminación de la publicidad no tuvo repercusiones directas positivas en la audiencia, ya que esta disminuyó cuatro décimas en relación con el año anterior.

Durante ese año La 1 optó por una programación mayoritariamente informativa ( $52.36 \%$ ) y lideró todas las ediciones informativas, aunque fueron los eventos deportivos (Champions, Liga de Campeones) los que consiguieron los más altos índices de audiencia. La ficción (17.24 \%) y el entretenimiento $(17.23 \%)$ fueron los otros dos géneros a los que se destinó 
más tiempo de programación con series como Águila Roja que consiguió aglutinar a un gran número de espectadores (más de seis millones de espectadores en algunos de sus episodios).

En 2011, primer año de la fusión de Gestevisión (Telecinco) y Sogecuatro (Cuatro), La 1 continuó siendo la cadena más vista del año por tercer año consecutivo a pesar del descenso generalizado de la audiencia derivada de la fragmentación. Obtuvo un liderazgo mensual a excepción de los meses de verano (junio, julio y agosto), en los que el ranking lo encabezó Telecinco. Al igual que en el año anterior, el contenido informativo fue el predominante (47.8\%) con mayor peso de la ficción (19\%) y los informativos de la cadena continuaron siendo los más vistos en todas las ediciones. Cabe señalar que de los 50 programas más vistos del año, 45 fueron emitidos por La 1, y la mayoría de ellos fueron partidos de fútbol y la serie Águila Roja.

El 2012 supuso el inicio del declive de la audiencia de la cadena, ya que pasó de ser la más vista a una tercera posición, lo cual produjo un brusco cambio en el liderazgo. La atomización del mercado audiovisual marcó este descenso de audiencia generalizado, aunque en la cadena pública fue extraordinariamente impactante al perder casi cuatro puntos en dos años. Telecinco fue la cadena con más audiencia anual basando su éxito en formatos de entretenimiento y de telerrealidad, señas de identidad de la cadena.

En 2013, se confirmó la tendencia del año anterior y supuso la consolidación del duopolio Mediaset España y Atresmedia al concentrar a más de la mitad de los espectadores españoles (57.8 \%). Las principales cadenas de ambos grupos (Telecinco y Antena 3 ) terminaron el año con una única décima de diferencia (Telecinco: $13.5 \%$ y Antena 3: 13.4\%) (tabla 3). La cadena pública continuó perdiendo audiencia y tampoco consiguió liderar ningún mes del año y terminó 2013 con una cuota de pantalla anual de $10.2 \%$. La cuota de pantalla de todo el grupo CRTVE sumó únicamente $16.7 \%$. El género que más retransmitió fue el informativo ( $40 \%)$, en el que continuó siendo líder, seguido del entretenimiento (22.8\%). Sin embargo, los mejores datos de audiencia los consiguió con la retransmisión de eventos deportivos como la Copa del Rey o La Liga de Campeones. 
Tabla 3. Cuota de pantalla de los principales canales generalistas españoles en abierto durante el periodo 2010-2015

\begin{tabular}{|c|c|c|c|c|c|c|}
\hline & $\mathbf{2 0 1 0}$ & $\mathbf{2 0 1 1}$ & $\mathbf{2 0 1 2}$ & $\mathbf{2 0 1 3}$ & $\mathbf{2 0 1 4}$ & $\mathbf{2 0 1 5}$ \\
\hline Antena 3 & 11.7 & 11.5 & 12.5 & 13.4 & 13.6 & 13.4 \\
\hline Telecinco & 14.6 & 14.2 & 13.9 & 13.5 & 14.5 & 14.8 \\
\hline La Sexta & 6.6 & 5.7 & 4.9 & 6 & 7.2 & 7.4 \\
\hline Cuatro & 7 & 6.1 & 6 & 6 & 6.7 & 7.2 \\
\hline
\end{tabular}

Fuente: Elaboración propia según Barlovento Comunicación.

En 2014, el duopolio se afianzó (58.4\% de audiencia) y la audiencia del grupo CRTVE continuó estable debido al "apagón temático" que tuvo lugar el 9 de mayo de 2014 y que supuso la desaparición de nueve cadenas temáticas (Nitro, Xplora, la Siete, La Nueve y laSexta3, entre otras), tras la aplicación de la sentencia del Tribunal Supremo que anuló el acuerdo del Consejo de Ministros de 16 de julio de 2010. Esta situación implicó que todas las otras demás cadenas absorbieran la audiencia de los canales cerrados. Sin embargo, lo más destacable del año fue que los informativos de La 1 perdieran su liderazgo a favor de Telecinco.

Finalmente, en 2015, La 1 alcanzó un mínimo histórico anual (9.8 \%), aunque apenas perdió presencia en el conjunto de las cadenas. La 1 terminó el año en la tercera posición del ranking y únicamente a 2.4 puntos de laSexta, canal que en diez años ha conseguido posicionarse fuertemente en el panorama audiovisual español. La pérdida de liderazgo de informativos por parte de La 1 volvió a confirmarse este año.

\section{La 2: programación y comportamiento de la audiencia}

La 2, la cadena cultural por excelencia, también ha ido perdiendo audiencia progresivamente durante el periodo 2010-2013 hasta recuperar parte de los espectadores en los últimos dos años. Los contenidos ofertados por esta cadena se alejan de los programados por cualquier otro grupo audiovisual al emitir contenidos con carácter cultural, de divulgación científica, no muy habituales en las parrillas de programación de las cadenas generalistas y temáticas orientadas principalmente al entretenimiento. Por ello, los contenidos emitidos en esta cadena son los que mejor se ajustan a los re- 
querimientos de la comunicación de servicio público (Fernández y Roel, 2014; Walzer y Retis, 2007) y hacen de ella una cadena para las minorías.

En relación con las franjas horarias programáticas del canal, la mañana tiene dos bloques diferenciados. El primero de ellos dedicado a programas educativos (That's english) o de carácter empresarial (Aquí hay trabajo) y la segunda al espacio diario Para todos $L a$ 2, que estuvo en antena desde 2010 a 2015. La franja de sobremesa y de tarde está destinada al concurso Saber y ganar, uno de los concursos más longevos de la historia de la televisión en España, seguido de los documentales. Por la noche, se destina principalmente a programas relacionados con el cine (Versión española) o con aspectos culturales.

Las claves de su programación residen en potenciar la innovación en los formatos, por ejemplo Torres y Reyes (2013) o Órbita Laika (2014), espacios creativos alejados de los tradicionales parámetros de producción y que tratan de fomentar la participación ciudadana, uno de los factores diferenciales que debe poseer un servicio público (Perales, 2016), ya que legitima su existencia y complementa la universalidad de su acceso (De Bustos y Casado, 2012).

Los compromisos culturales de la cadena hacen de ella un referente cultural de la oferta programática en España. A pesar de su marchamo de televisión de calidad y de la presencia de contenidos altamente innovadores, ha ido perdiendo progresivamente audiencia y se ha visto superada por las cadenas temáticas de reciente creación. La apuesta por contenidos culturales, como destacan Fernández y Díaz-Campo (2014), no es una misión sencilla para ninguna televisión, y mucho menos para una pública al tener que tratar de materializar de forma simultánea el aumento de competitividad y los medios presupuestarios.

Cabe mencionar que la oferta de contenidos del canal sufrió modificaciones relevantes durante los cinco años analizados, puesto que muchos de los espacios infantiles, deportivos e informativos emitidos tradicionalmente por La 2 fueron trasladados a las otras cadenas del grupo, como se verá a continuación. 


\section{La oferta temática de la Corporación RTVE}

La oferta temática de la Corporación RTVE se distribuye en tres canales (Clan, Teledeporte y 24 horas) creados con anterioridad al apagón analógico.

\section{Clan}

El canal Clan, creado en 2005, está específicamente diseñado para el público infantil y juvenil (4 a 12 años) y absorbió los espacios infantiles y juveniles que anteriormente se emitían en La 2. Los contenidos educativos y de entretenimiento son los predominantes, aunque "como servicio público deben primar los contenidos de producción propia que contribuyan al conocimiento" (Fernández, 2013, p. 321). Las series de entretenimiento y de animación, de producción propia (Jelly Jamm o Clanners) o externa (Peppa Pig o Bob Esponja) son el buque insignia del canal.

Tabla 4. Cuota de pantalla de los principales canales temáticos infantiles en España durante el periodo 2010-2015 en porcentaje

\begin{tabular}{|l|c|c|c|c|c|c|}
\hline & $\mathbf{2 0 1 0}$ & $\mathbf{2 0 1 1}$ & $\mathbf{2 0 1 2}$ & $\mathbf{2 0 1 3}$ & $\mathbf{2 0 1 4}$ & $\mathbf{2 0 1 5}$ \\
\hline Boing (Mediaset España) & 0.2 & 1.1 & 1.7 & 1.7 & 1.7 & 1.6 \\
\hline Clan & 3.2 & 3.2 & 2.5 & 2.4 & 2.3 & 2.4 \\
\hline Disney Channel (Net TV) & 2.1 & 1.7 & 1.6 & 1.5 & 1.5 & 1.4 \\
\hline
\end{tabular}

Fuente: Elaboración propia según Barlovento Comunicación.

$\mathrm{Al}$ contrario que otras cadenas del grupo, Clan sí consiguió superar a sus principales competidores (Boing y Disney Channel) al ser el canal temático infantil con mayor cuota de pantalla en España durante el periodo estudiado, a pesar de la pérdida de audiencia derivada de la multiplicación de los canales tras el encendido digital (tabla 4).

\section{Teledeporte}

Tras el apagón analógico Teledeporte acogió gran parte de la programación deportiva que se emitía en La 2. En la programación de este canal, tienen cabida otros deportes de carácter minoritario (atletismo, balonmano, de- 
porte femenino, paraolímpico, ciclismo, golf, etc.) que dejan para La 1 la retransmisión de los grandes eventos deportivos que suponen siempre récords de audiencia. De ahí que las cuotas de audiencia del canal sean mínimas, de tal modo que no llegue a alcanzar ni a $1 \%$ de la audiencia.

En 2014, se anunció el cierre del canal y su emisión únicamente a través de internet debido a los recortes presupuestarios. Sin embargo, debido al cambio de presidente de la Corporación, finalmente no se llevó a cabo tal decisión que supondría el cierre del único canal deportivo no de pago de España en aquel momento.

\section{Horas}

Es el único canal temático exclusivamente informativo de toda la oferta televisiva española televisión digital terrestre en abierto. En su estrategia de programación, se combina la cobertura a acontecimientos de especial relevancia con la información en directo con continuas conexiones a las diferentes corresponsalías con las que cuenta la Corporación.

Como señaló Soengas (2013), este canal es un ejemplo emblemático de la programación informativa de la televisión digital terrestre basada en 35 \% en la redifusión de los contenidos. Mediante esta fórmula se "programa los informativos en forma de bucle sin actualizar las noticias, creando una sensación de directo permanente que no se corresponde con la realidad" (p. 155).

Entre sus programas más representativos destacan La noche 24 horas, Zoom Net o Zoom Tendencias.

Su cuota de audiencia también resulta insignificante pero sí consigue incrementar considerablemente sus datos con la cobertura de acontecimientos, como los recientes atentados de París (2015), en los que batió récord histórico de audiencia ( $2.8 \%$ de cuota de pantalla), debido a que fue uno de los pocos canales que modificó su programación habitual para ofrecer un seguimiento en directo. 


\section{Discusión y conclusiones}

A causa de los datos expuestos, la hegemonía de La 1 como el canal generalista más visto en España se ha visto claramente debilitada en los últimos años. La eliminación de la publicidad comercial parecía ser a priori una ventaja competitiva ante el espectador, que podría relacionarse también como un incremento en la percepción de calidad; sin embargo, y a la vista de los resultados obtenidos, esto no fue así.

La vertiginosa caída de la audiencia de más de seis puntos en los últimos años pudo estar ocasionada, por una parte, por la falta de estabilidad en su parrilla de programación que dificultó la fidelidad y también la implicación del espectador; y por otra, el recorte en los presupuestos de la cadena que afectaron a la mayoría de las series de producción propia.

Además, la pérdida de liderazgo de los informativos es un claro indicativo de la falta de reconocimiento social y de confianza de la ciudadanía, puesto que uno de los objetivos prioritarios de la Corporación reside en potenciar y mantenerlos como referencia incuestionable al ser la preferencia absoluta y el elemento distintivo (Radio y Televisión Española, s/f). Los espacios informativos de la Corporación no deberían perder esa capacidad de liderazgo en el panorama audiovisual español, ya que son una de las claves del servicio público. La falta de neutralidad y de pluralismo interno parecen ser, a la vista de la documentación y literatura científica consultada, algunas de las causas principales de dicho desapego, aunque sería preciso elaborar en próximas investigaciones un análisis desde la perspectiva de los públicos.

A la vista de los datos analizados, las preferencias de los espectadores españoles parecen adecuarse más a los contenidos emitidos por los grupos empresariales Atresmedia y Mediaset España. Sus estrategias de programación están vertebradas sobre la ficción y el entretenimiento en busca continuamente de la espectacularización de los contenidos, espacios que consiguen que las cadenas principales de ambos grupos lideren los índices de las audiencias. 
La rentabilidad de sus canales principales (no tanto la de sus otras cadenas temáticas que replican contenidos y son espacios contenedores de las cadenas principales) confirman la dualidad del sistema audiovisual español que produce una situación claramente paradójica, puesto que existen numerosos canales en el mercado, pero cada vez se consolida más este duopolio.

La televisiva pública debe tener en cuenta además que la competencia directa ya no reside únicamente en los operadores privados sino en nuevos servicios de transmisión libre, en las nuevas pantallas como los dispositivos móviles y en el crecimiento reciente de la penetración de la televisión de pago en España. A lo que hay que añadir dos aspectos contextuales relevantes: por un lado, que la audiencia está sufriendo un proceso de hiper-fragmentación que hace cada vez más difícil establecer sinergias sólidas entre estas y los medios televisivos debido a la intensificación de la competencia; y por otro lado, el empoderamiento del telespectador que decide qué contenidos desea ver, cuándo y cómo, y que además participa activamente en dichos contenidos y obtiene un control desconocido hasta el momento como receptor televisivo y hace más compleja la actividad de los programadores.

En este nuevo escenario mediático digitalizado, es difícil discernir el papel que desempeñará la televisión pública española. Los diferentes Gobiernos han intentado reestructurar y transformar el ente público durante décadas sin demasiado éxito. La reciente reestructuración que se llevó a cabo durante los años de precariedad económica debilitó a la Corporación y obliga a reflexionar sobre su redefinición como servicio público, donde además dicha concepción y función de servicio público debe adaptarse al nuevo entorno digital en el cual intervienen otros agentes anteriormente desconocidos. En el informe Teledetodos, elaborado por un grupo de académicos e investigadores españoles, se plantean y presentan propuestas detalladas para esta nueva concepción del servicio público.

Además, la crítica continuada al modelo de financiación acrecienta los rumores continuos sobre la vuelta de la publicidad. La Asociación Española de Anunciantes, principal referente de los anunciantes en España, aboga por dicha recuperación como una posibilidad efectiva y real si se rea- 
liza de un modo controlado y razonado que mejoraría la parrilla televisiva y aumentaría la audiencia (Anunciantes.com, 2014).

En definitiva, los datos aportados por este artículo deberían invitar a la reflexión sobre la valoración de la oferta televisiva de la corporación pública que lleva camino de convertirse en puramente testimonial o residual por su escasa presencia social. La oferta de contenidos de un servicio público debe ser claramente diferente de la oferta de los canales comerciales; sin embargo, los índices de audiencia, en vez de legitimar el alcance de su función social, parecen ser un síntoma del alejamiento de la ciudadanía.

En investigaciones futuras, sería interesante completar esta investigación con un análisis cualitativo de la audiencia que permitiera profundizar en la valoración que esta audiencia realiza sobre los contenidos televisivos y su grado de satisfacción e intentar observar la correlación entre este dato y los índices de audiencia.

\section{Referencias}

Aimc.es (2016). Marco general de los medios en España. Recuperado de http:// www.aimc.es/-Descarga-Marco-General-Asociados-html

Anunciantes.com (2014). ¿Por qué es necesario que vuelva la publicidad a TVE? Recuperado de http://www.anunciantes.com/nota-de-prensa/2011-14-por-que-es-necesario-que-vuelva-la-publicidad-a-tve/

Barlovento Comunicación (2010). Análisis televisivo 2010. Documento facilitado a la autora por correo electrónico.

Barlovento Comunicación (2011). Análisis televisivo 2011. Recuperado de http://www.barloventocomunicacion.es/images/publicaciones/ANALISIS_TELEVISIVO_2011[2].pdf

Barlovento Comunicación (2012). Análisis televisivo 2012. Documento facilitado a la autora por correo electrónico. 
Barlovento Comunicación (2013). Análisis televisivo 2013. Recuperado de http://www.barloventocomunicacion.es/blog/82-analisis-televisivo-2013-actualizado.html

Barlovento Comunicación (2014). Análisis televisivo 2014. Recuperado de http://www.barloventocomunicacion.es/images/publicaciones/analisis-televisivo-2014-Barlovento.pdf

Barlovento Comunicación (2015). Análisis televisivo 2015. Recuperado de http://www.barloventocomunicacion.es/images/publicaciones/analisis-televisivo-2015-Barlovento.pdf

Cnmc.es (2015). Informe económico de las telecomunicaciones y del sector audiovisual 2015. Recuperado de http:// data.cnmc.es/datagraph/ files/Informe \%20Telecos \%20y \%20Audiovisual \%202015.pdf

Bustamante, E. (1999). La televisión económica. Barcelona: Gedisa.

Bustamante, E. y Corredor, P. (2012). La política audiovisual de los gobiernos de Zapatero: balance de una segunda legislatura. En M. Lamuedra (ed.), El futuro de la televisión pública: la necesaria alianza con la ciudadanía (pp.61-86). Madrid: Popular.

Callejo, J. (2007). Transformaciones del sistema televisivo español: una explicación estructural. Comunicación y Sociedad, 7, 197-226.

Cascajosa Virino, C. (2016). Buscando al espectador serial desesperadamente: la nueva investigación de audiencias y la serie El Ministerio del Tiempo. Revista Dígitos, 2, 53-69.

Coller, X. (2000). Estudio de casos. Madrid: Centro de Investigaciones Sociológicas.

De Casas Moreno, P., Maraver López, P. y Aguaded Gómez, J. I. (2016). Análisis de contenido de la programación sensacionalista pública 
española: propuesta de cuestionario como medidor de los hábitos de la audiencia audiovisual. Icono 14, 14, 1-23.

De Bustos, J. C. y Casado del Río, M.Á. (2012). Televisión pública y participación. En M. Lamuedra (ed.), El futuro de la televisión pública: la necesaria alianza con la ciudadanía (pp. 211-236). Madrid: Popular.

Díaz Arias, R. (2012). Contenido jurídico del servicio público de la radiotelevisión en España: las obligaciones de los operadores públicos y privados. Madrid: Icono 14.

Fernández Gómez, E. F. (2013). El primer año de la Corporación RTVE: cambios en la programación de La 2. Historia y Comunicación Social, 18, 723-736.doi: http://dx.doi.org/10.5209/rev_HICS.2013. v18.44003

Fernández Gómez, E. F. y Díaz-Campo, J. (2014). La 2 de RTVE como agente de difusión cultural: los efectos del cambio del ente público RTVE a la corporación RTVE (2006-2007). En Congreso Virtual Eumednet. IV Arte y Sociedad: Bellas Artes y Sociedad Digital. Recuperado de https://hal.archives-ouvertes.fr/hal-01345516/document

Fernández, L.y Roel, M. (2014). Las actuales estrategias de programación de la TDT en España: entre la comunicación de servicio público y la temática oferta privada. Razón y Palabra, 86, 37-25.

García Avilés, J. A. (2011). Dimensiones y tipología de las actividades de participación de la audiencia en la televisión pública. Ámbitos, 20, 175-195.

García-Santamaría, J. V. (2013). Televisión y concentración en España: el duopolio de Mediaset y Atresmedia. Palabra Clave, 16(2), 366-397.

Gómez-Escalonilla, G. (1998). La programación televisiva en España: estudio de las parrillas de programación televisiva española desde 1956 a 
1996 (Tesis de doctorado, Universidad Complutense de Madrid, Madrid, España).

Herrero, M. y Urgellés, A. (2015). La audiencia y hábitos de consumo. En M. Medina (ed.), La audiencia en la era digital (pp. 67-83). Madrid: Fragua.

Huertas Bailén, A. (2002). La audiencia investigada. Barcelona: Gedisa.

Infoadex.es (2015). Estudio Infoadex de inversión publicitaria en España. Recuperado de http://www.infoadex.es/estudios.html

Instituto Oficial Radio y Televisión (IORTV) (s/f). Principios básicos programación de RTVE. Recuperado de http://www.rtve.es/ contenidos/documentos/Principios_basicos_de_la_programacion_de_RTVE.pdf

López Gil, N. y Valderrama, M. (2011). La nueva televisión pública española: Ley de Financiación, flujo de las audiencias y análisis de las promociones de canal tras la supresión de publicidad. Revista Comunicación, 9, 205-221.

López-Vidales, N., Azurmendi-Adarraga, A.y Ortiz-Sobrino, M.Á. (2012). Hacia un nuevo marco regulatorio y de gestión de la televisión pública en España: el bienio del cambio. Revista de Comunicación de la SEECI, 27, 39-59.

Palacio, M. (2007). La televisión pública española (TVE) en la era de José Luis Rodríguez Zapatero. Journal of Spanish Cultural Studies, 8(1), 71-83. doi: 10.1080/14636200601148843

Perales, A. (2016). La participación ciudadana como factor diferencial de los medios públicos. AdComunica: Revista Científica de Estrategias, Tendencias e Innovación en Comunicación, 11, 177-182. doi: http:// dx.doi.org/10.6035/2174-0992.2016.11.12 
Quintas-Froufe, N. (2013). La audiencia ante el "apagón publicitario" en España: un primer balance. Observatorio Journal, 7(1), 65-83.

Radio y Televisión Española (RTVE) (s/f). Estatuto de información de la Corporación RTVE. Recuperado de http://www.rtve.es/contenidos/documentos/ESTATUTO_DE_INFORMATIVOS_v1.pdf

Roel, M. (2014). Audiencia y programación en Televisión Española: del ocaso del modelo paleotelevisivo al umbral del neotelevisivo. Estudios del Mensaje Periodístico, 20, 157-175. doi: http://dx.doi. org/10.5209/rev_ESMP.2014.v20.45096

Rueda Laffond, J. C. y Coronado Ruiz, C. (2016). Historical science fiction: From television memory to transmedia memory in El Ministerio del Tiempo. Journal of Spanish Cultural Studies, 17, 87-101. doi: 10.1080/14636204.2015.1135601

Sánchez-Tabernero, A. (2015). Calidad de los medios audiovisuales y economía de la abundancia. En M. Medina (ed.), La audiencia en la era digital (pp.39-65). Madrid: Fragua.

Soengas, X. (2103). El nuevo escenario informativo en España después de la implantación de la televisión digital terrestre. Ámbitos: Revista Internacional de Comunicación, 22, 151-160.

Soler Rojas, P. (2012). RTVE en tiempos revueltos. En M. Lamuedra (ed.), El futuro de la televisión pública: la necesaria alianza con la ciudadanía (pp. 87-100). Madrid: Popular.

Teledetodos.es (2015). Un nuevo modelo para un tiempo nuevo. España 2015: diagnóstico del servicio público de radio, televisión y servicios interactivos. Propuestas para una ciudadanía democrática. Recuperado de http://teledetodos.es/index.php/blogs/ item/1192-un-nuevo-modelo-para-un-tiempo-nuevo-espana2015-diagnostico-del-servicio-publico-de-radio-television-y-servicios-interactivos-propuestas-para-una-ciudadania-democratica 
Villagrasa, J. M. (2011). ¡Atrápalos como puedas! La competencia televisiva: programación y géneros. Valencia: Tirant Lo Blanch.

Walzer, A. y Retis, J. (2007). Modelos de servicio público en Europa: análisis comparativo de TVE y BBC. Comunicar: Revista Científica Iberoamericana de Comunicación y Educación, 3(16), 715-726. 